\title{
REFLEXIONES ACERCA DE LOS PROBLEMAS MONETARIOS INTERNACIONALES EN LA ACTUALIDAD.
}

\section{REFLECTIONS ON CURRENT INTERNATIONAL MONETARY PROBLEMS.}

\section{Rafael Alfonso Casanova Montero, PhD.}

Doctor en Ciencias Económicas (Cuba). Docente titular de la Facultad de Ciencias Económicas en la Universidad de Guayaquil, Ecuador. alfonso.casanovam@ug.edu.ec

Hermes René Aguilar Azuero, Mgs. Magíster en Negocios Internacionales y Gestión de Comercio Exterior (Ecuador). Docente titular de la Facultad de Ciencias Económicas en la Universidad de Guayaquil, Ecuador. hermes.aguilara@ug.edu.ec

\section{Sergio Pino Peralta, Mgs.}

Magíster en Economía Agraria y Desarrollo Rural (Ecuador). Docente titular de la Facultad de Ciencias Económicas en la Universidad de Guayaquil, Ecuador. sergio.pinop@ug.edu.ec

Ismael Zuaznábar Morales, Lic. Licenciado en Economía Política (Cuba). Docente de la Facultad de Ciencias Económicas en la Universidad Central de

Venezuela, Venezuela. guaraiarepano1@yahoo.es 


\section{ARTÍCULO DE REFLEXIÓN}

Recibido: 12 de febrero de 2017.

Aceptado: 30 de abril de 2017.

\section{RESUMEN}

El objetivo de este artículo es hacer un breve análisis de la situación monetaria internacional, en particular sobre la crisis mundial, la tensa relación entre Rusia y Estados Unidos, la aparición de China en el escenario económico global, el deterioro de las materias primas, el incremento de la pobreza y la inequidad, entre otros aspectos no menos importantes. Para este cometido, se utilizan metodologías de orden descriptivas, de fuentes de información que autores y organismos internacionales que trabajan en estos temas. Los resultados muestran que vienen años de cambios significativos en la economía mundial globalizada, y por tanto de reajustes de la importancia relativa de las monedas que se utilizan mayormente en los movimientos de mercancías y capitales globales por lo que es de esperar acomodos y reacomodos entre el dólar, la libra esterlina, el euro, el yuan, el yen y el rublo, buscando el predomino mundial, sin dejar de lado a otras monedas que lucharan por mantener su territorio fuera de la penetración de los demás.

Palabras clave: crecimiento económico, comercio de bienes y servicios, política monetaria, economía internacional.

\section{ABSTRACT}

The purpose of this article is to give a brief analysis of the international monetary situation, in particular on the global crisis, the tense relationship between Russia and the United States, the emergence of China in the global economic scenario, deterioration of raw materials, Increase of poverty, among other aspects no less important. For this purpose, methodologies of descriptive order, of sources of information that authors and international organisms that work in these subjects are used. The results show that there have been years of significant changes and 
changes in the globalized world economy, and consequently, of the relative importance of the currencies that are mostly used in global merchandise and capital movements. Between the dollar, the pound sterling, the euro, the yuan, the yen and the ruble, seeking world domination, without neglecting other currencies that struggled to keep their territories out of the penetration of others.

Keywords: economic growth, trade in goods and services, monetary policy, international economy.

\section{INTRODUCCIÓN}

Para analizar la situación monetaria internacional, es necesario partir de la dinámica presente y de la coyuntura de la economía mundial, la cual pasa por un momento de ajuste global ante la existencia de una fuerte competencia entre las grandes economías del mundo y las múltiples contradicciones derivadas de ello, destacándose dentro de estas las siguientes: La presencia latente de la crisis económica mundial de 2008, las contradicciones entre Rusia y Estados Unidos con apoyo europeo y el bloqueo y sanción occidental a Moscú, el creciente peso de China en el comercio de bienes y servicios, la exportación e importación de capitales y su rápido dinamismo internacional y como principal tenedor de la deuda estadounidense y como el principal reto económico de Washington, los problemas ambientales y el incumplimiento de las metas sobre el del control del calentamiento global.

Todos estos complejos problemas, de una u otra forma, tienen expresión en la circulación mundial del dinero, de ahí la importancia de partir de ello, para analizar algunos de los principales problemas monetarios del mundo actual, considerando que estos se mueven con la velocidad de un rio crecido, generando el peligro de arrastrar a su paso a más de un país, si no se toman las medidas preventivas pertinentes.

\section{REVISIÓN TEÓRICA}

La presencia latente de la crisis mundial. 
Desde el año 2008 el crecimiento económico global enfrenta múltiples dificultades en su reproducción, para algunos especialistas no ha terminado de ser superada en Estados Unidos y menos aún en Europa, donde la fragilidad del crecimiento y la posibilidad de una nueva recesión están, según se dice, a la orden del día.

Así el panorama mundial muestra que Europa enfrenta una posible deflación, Japón no está lejos de una recesión y una desaceleración en la economía de China, la segunda mayor del mundo, por lo que existen temores de que la recuperación de la profunda crisis de fines de la década pasada esté perdiendo impulso.

"La economía global sigue cauta y está sujeta a considerables riesgos bajistas que podrían golpear el crecimiento y la confianza global", dijo el borrador del comunicado preparado para ser divulgado por el comité de desarrollo del FMI y el Banco Mundial. (Wroughton, 2014)

"La senda del crecimiento económico, la creación de empleos y la prosperidad común necesitará de un esfuerzo multilateral sostenido para proteger a los más pobres y a los más vulnerables", agregó.

\section{Las contradicciones Rusia-Estados Unidos con apoyo europeo y el bloqueo y sanción occidental a Moscú.}

El 4 de diciembre del 2014, la Cámara de Representantes de Estados Unidos, aprobó la Resolución 758, en este documento "Se condena la agresión política, económica y militar de la Federación Rusa contra Ucrania, Georgia y Moldavia y las violaciones de su soberanía, independencia e integridad territorial" (TeleSUR, 2014)

La política de desestabilización contra Rusia ha sido reconocida por la alta funcionaria estadounidense Victoria Nuland, Secretaria de Estado Adjunta Para Asuntos Europeos, quien confesó en la Conferencia del Club de la prensa en Washington en diciembre del 2013, que Estados Unidos a través de agencias de inteligencia y la USAID, había apoyado con 5 mil millones de dólares a las fuerzas pro europeas ucranianas para alejar a ese país de la influencia rusa. (Leal, 2015) 
Para Alexei Puskov, Presidente de la Comisión de Asuntos Internacionales del parlamento ruso "La resolución 758 viene a ser una formalización oficial de la nueva Guerra Fría, iniciada por la Administración Obama contra Rusia. Tras la aprobación de este documento, un "reinicio" de las relaciones entre Rusia y Estados Unidos "no tiene posibilidad alguna", sentenció el diputado. (TeleSUR, 2014)

Previo a la resolución 758, el Congreso Estadounidense había aprobado la denominada Ley de Prevención de la Agresión Rusa (Rapa por sus siglas en inglés) que ingresó al Senado mediante el número S 2277 y allí se convocó a la militarización de Europa del Este y los países bálticos, autorizando, además la presencia de tropas estadounidenses y de la OTAN en las fronteras rusas en evidente provocación. (Ley de prevención de la agresión Rusa, 2014)

Para el gobierno ruso, el propósito de las sanciones en su contra y el cerco militar están destinada s a crear las condiciones para el cambio de poder en ese país y al respecto el viceministro ruso de Relaciones Exteriores, Serguéi Riabkov afirmo que "Realmente no se oculta el hecho de que Estados Unidos quiere crear las condiciones económicas y sociales para la realización del cambio de poder en Rusia, pero, nuestro país percibe con calma la situación respecto a las relaciones (...). No nos sentimos nerviosos en este sentido. Recordemos que el enfriamiento en las relaciones entre Moscú y Washington empezó mucho antes del inicio del conflicto en Ucrania". (TeleSUR, 2014)

\section{El creciente peso de China en la arena internacional en el comercio y finanzas internacionales.}

Durante el tercer trimestre de 2014 el crecimiento económico de China disminuyó hasta un $7,3 \%$, y los pobres resultados del mes de noviembre, relacionados con las cifras de pedidos de las fábricas y de inversión, indican inequívocamente que el crecimiento anual no alcanzaría la meta fijada por el gobierno chino de un 7,5\%, lo que supone el crecimiento más débil en 24 años. (BBC, 2014) 
El Banco Central de China manifestó que su crecimiento económico podría sufrir una desaceleración en 2015 hasta el 7,1\% desde el 7,4\% del 2014, ante la debilidad del sector inmobiliario. El informe también destaca que la creciente demanda mundial de productos podría dar un fuerte estímulo a las exportaciones chinas, pero, sin embargo, no parece que este hecho tenga suficiente fuerza para contrarrestar el efecto de la débil inversión inmobiliaria local. (Observatorio Económico Asia - Pacífico, 2014)

En el comercio exterior chino, se proyecta que las exportaciones crezcan un $6,9 \%$, desde el 6,1\% alcanzado en 2014, las importaciones se incrementarán un 5,1\% en 2015 , cifra muy superior al $1,9 \%$ de 2014 . Se espera que el incremento de los tipos de interés por la Reserva Federal impactara en las economías emergentes.

La inflación, otro de los indicadores principales de la economía de China, podría mantenerse estable el 2015 en torno al 2,2\% y la inversión en activos fijos podría caer desde el $15,5 \%$ de 2014 hasta el $12,8 \%$ en 2015. Por su parte, el crecimiento de ventas al por menor se espera que aumente desde el $12 \%$ hasta el $12,2 \%$, todo ello derivado del informe de su banco.

Remarcando lo anterior, el presidente chino, Xi Jinping, sostuvo en la reunión de directores generales del Foro de Cooperación Económica de Asia-Pacífico (APEC) realizada en noviembre de 2014, que su país esperaba importar 10 billones de dólares en productos de todo el mundo, mientras la inversión al exterior ascenderá a 1,25 billones de dólares en la próxima década.

\section{El deterioro de los precios de las materias primas.}

De este amplio tema, el más evidente es el del petróleo, que por su importancia tiene en vilo a más de un país, y en sentido general, presenta una relación de primer orden con las monedas del mundo y sobre todo con el dólar, pues el comercio se hace esencialmente en la moneda estadounidense, aunque con una relativa competencia del euro y las monedas de Rusia y China. Los precios del crudo han bajado de unos 100usd el barril a menos de la mitad y la tendencia es inestable. 


\section{El crecimiento de la pobreza mundial.}

Los ministros de Finanzas y Desarrollo de todo el orbe, debatieron en 2014 sobre los considerables riesgos y potencial crisis de la economía global, al respecto solicitaron un esfuerzo para proteger a los pobres del mundo, El comunicado de la cita concluyo que, un $20 \%$ de los países que reciben ayuda del FMI y del Banco Mundial, no han mostrado un crecimiento de la producción per cápita desde el 2000 y están en particular peligro de ser duramente golpeados si la recuperación global fracasa. El documento insto al Banco y al Fondo Monetario Internacional, a observar la vulnerabilidad de los países de bajos ingresos a las turbulencias, incluidos los peligros que su deuda pública pueda representar. (Legarde, 2014)

\section{Algunos elementos históricos de interés sobre el sistema monetario internacional.}

El patrón oro fue un sistema monetario que fijaba el valor de la unidad monetaria en términos de una determinada cantidad de oro. El emisor de la divisa garantizaba a los poseedores de la misma, la cantidad de oro consignada en ella. A comienzos del siglo $\mathrm{XX}$, todo el sistema internacional se basaba en el oro. Sin embargo, sólo Inglaterra, Alemania, Francia y Estados Unidos mantenían un patrón oro puro. Una alternativa era también el patrón bimetálico, en el que las monedas estaban respaldadas por una parte de oro y otra de plata, desde luego con una relación especifica entre estos metales.

Históricamente, la vigencia del patrón oro fue la base del sistema financiero internacional durante el siglo XIX y terminó a raíz de la Primera Guerra Mundial, puesto que los gobiernos beligerantes necesitaron imprimir mucho dinero fiduciario para financiar el esfuerzo bélico sin tener la capacidad de respaldar ese dinero en metal precioso. (Levi, 1997)

Después de la Guerra, el sistema se fragmento en Zonas y Áreas monetarias y fue sustituido por el Patrón Cambio Oro. Años después, con la nueva correlación de fuerzas políticas, económicas y militares, establecida con el fin de la Segunda 
Guerra Mundial, surgió el patrón dólar implantado en 1944, en Estados Unidos impuso su tesis de que el dólar era tan bueno como el oro, en 1946 con la Conferencia de Bretton Woods, en la que surgieron también los órganos del control del sistema, el Fondo Monetario Internacional y el Banco Mundial, que con algunas variantes, siguen funcionando hoy. Allí se adoptó un patrón oro-divisas, en el que Norteamérica debía mantener el precio del oro en 35.00 dólares la onza y se le concedió la facultad de cambiar dólares por oro a ese precio, sin restricciones ni limitaciones. El boom económico estadounidense de post guerra también se debió mucho al oro que tenía acumulado. (Selva, 2014)

Las divisas que garantizaban el cambio al oro, fueron el dólar y la libra esterlina el sistema dio lugar a una estabilidad relativa del sistema desde 1944 hasta 1971. Este periodo se conoce en la historia, como la "Edad de oro" del sistema monetario internacional.

Había una realidad objetiva de la economía mundial, Estados Unidos tras la guerra, emerge como la economía más fuerte del mundo. Ante su rápido crecimiento económico e industrial y una fuerte acumulación de capital, se convierte en el principal centro del movimiento de capital internacional. Todo ello se hizo en base al dólar, que además era aceptado sin dificultades en todas partes del mundo.

El peso y fortaleza del dólar no se puede separar del hecho de que la producción industrial norteamericana en 1945 alcanzo más del doble de la producción anual entre los años 1935 y 1939, además aporto cerca del 50\% del PIB mundial con menos del 7\% de la población. A fines de 2014 Washington aportaba alrededor del $22 \%$ del PIB mundial, se calculó que la Reserva Federal imprime anualmente un millón de millones de dólares. La importancia del dólar llegó a tal extremo, que actualmente las reservas de todos los Bancos Centrales de 193 países del mundo, en el $67 \%$ son en dólares, un $15 \%$ en euros y un $18 \%$ en monedas nacionales. Estados Unidos logró crear así un sistema internacional financiero que no permite el colapso de su economía a pesar de su déficit comercial de más de 500 mil 
millones de dólares y de su deuda interna y externa que es más de 70 millones de millones de dólares. (Mishkim, 2008)

El resto de los países del mundo se entrelazaron tanto con la Reserva Federal norteamericana que no pueden dejar de financiarla a costa de sus ahorros para prevenir el colapso del existente Sistema Financiero Mundial. Se calcula que diariamente llegan a las arcas norteamericanas 2,5 mil millones de dólares de otros países. (Selva, 2014)

La recuperación de Europa de la guerra y la guerra en Vietnam en los 60 y 70 del siglo XX, más la emisión de miles de millones de dólares inorgánicos para financiarla, llevo a que el gobierno de Estados Unidos decrete la inconvertibilidad del dólar en 1971, ante la imposibilidad de seguir dejando que sus reservas se fueran al exterior. Considérese que, según la Reserva Federal, en 1945 el Fort Knox llegó a almacenar 20,000 toneladas de oro que se redujeron para el 2013 a 4,175 toneladas. A la vez, según la Web oficial de la Casa de la Moneda de Estados Unidos, había unas 5,000 toneladas métricas de oro en las bóvedas del Federal Reserve Bank of New York. (Selva, 2014)

El costo aproximado de la guerra se calculó en junio de 1974, por el Departamento

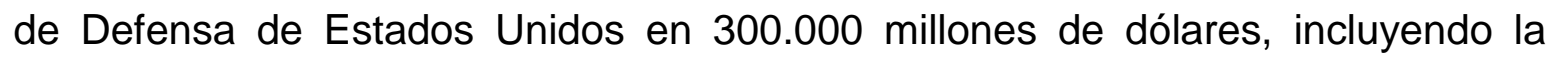
inevitable inflación, la producción perdida, el pago de los préstamos y las pensiones a los veteranos de guerra.

Tras la eliminación del patrón oro puro, el sistema monetario internacional se hace más frágil ante la inconvertibilidad de todas las monedas de referencia, de ahí en adelante, empezaron a primar otros elementos en la aceptación de una moneda u otra como medio de circulación y pago internacional, prevaleciendo durante mucho tiempo el dólar y la libra esterlina, hasta que surgió el euro y sustituyo a las monedas nacionales de los países miembros de la Unión Europea. En ese momento más de uno dijo que el euro era el fin de la hegemonía del dólar y tras los hechos europeos más recientes, al parecer estos pronósticos podrían haberse equivocado. 
No obstante, el papel internacional del euro aumenta cada día, ya que, a pesar de su corta existencia, la moneda única representa cerca del $30 \%$ de las transacciones en los mercados internacionales y del $10 \%$ de las reservas de divisas mundiales.

La existencia de la moneda única permitió a Europa enfrentarse a situaciones económicas internacionales complejas, como la crisis de 1998, el shock petrolífero del 2000, la crisis desatada a raíz del ataque terrorista a las Torres Gemelas de Nueva York en 2001 y luchar contra cris europea de los últimos años. El euro ha contribuido a que "Europa se haya adaptado de forma más estable a las circunstancias, lo que ha contribuido a una mayor estabilidad mundial" pero su circulación no deja de ser contradictoria y problemática, cuando algunos europeos amenazan con volver sus signos monetarios antiguos.

Sin embargo y a pesar de la relevante función internacional del euro, como muchos otros, opinamos que es " muy precipitado y pronto" para hablar sobre la muerte del dólar y su eliminación del comercio mundial.

\section{Principales problemas monetarios internacionales.}

Hoy, el poder relativo de las principales monedas, no está relacionado totalmente con el total de oro disponible en un país, prueba de ello es que, en 2014 Rusia supero a China en términos de reservas de oro y ocupo el sexto lugar en el ranking mundial de los mayores poseedores de reservas de este metal con $1.094,7$ toneladas ( $10 \%$ del total de las reservas internacionales). Ello no se refleja automáticamente en el rol de esta moneda en los mercados de divisas

El principal regulador financiero, Estados Unidos, disponía de la mayor parte del oro monetario: 8.133,5 toneladas, según los datos del Consejo Mundial de Oro. Además, mantiene en la base militar Fort Knox (estado de Kentucky), junto con sus propias reservas, el oro del Banco Central de Alemania que ocupa el segundo puesto en el ranking con $3.384,2$ toneladas.

\section{¿Está en crisis el dólar?}


La consecuencia de la inconvertibilidad del dólar en oro, decretada por Estados Unidos, se expresa en que el sistema monetario global de hoy no es el mismo desde hace unos años, se generalizo la fluctuación de las tasas de cambio y Estados Unidos, cuando Richard Nixon eliminó la convertibilidad del dólar en oro el 15 de agosto de 1971 podía imprimir la cantidad de dólares que quisiera sin ningún tipo de control internacional, así financió las guerras internacionales con los efectos ya señalados.

Lo que era imposible bajo el patrón oro, se hizo perfectamente posible bajo el dominio monetario del dólar, por ejemplo, los japoneses se convirtieron en gigantescos productores y transformaron a su país en una gran factoría. Ese proceso incrementó la desindustrialización de Estados Unidos y por ende minoro su capacidad competitiva internacional y el poder de pago del dólar y su uso en la economía global. El ejemplo, la fabricación de televisores con marcas como Westinghouse, Philco y Motorola fueron desplazados por la producción japonesa con marcas como, Víctor Company y Sony.

En estas condiciones se dio la crisis de los acuerdos de Brettón Woods que buscaba que los países miembros del FMl y el BM lograran equilibrios estructurales de balanza de pagos, trajo consigo el inicio de los desequilibrios, que fueron camuflados inicialmente por el acceso al crédito que facilitó Washington. Estados Unidos se embarcó en una expansión a gran escala del crédito, y a medida que la economía destruía puestos de trabajo en la industria, el sector financiero permitía un acceso al crédito que camuflaba el estancamiento y estimulaba las importaciones procedentes de Asia y el resto del mundo, lo que hundía aún más a la industria estadounidense. No es casual que, en términos reales, los trabajadores estadounidenses no hayan tenido ningún aumento real de sus ingresos desde 1970.

El auge de la expansión del crédito y el consumo fue visto con buenos ojos y los desequilibrios estructurales fueron vistos como transitorios. Nunca pensaron en las consecuencias no previstas de un consumo desenfrenado que lo llevaría a consumir la mitad del PIB mundial y acumular una deuda del tamaño de su PIB. 
Nadie previó que aquella enorme ventaja adquirida por Estados Unidos (comprar en el mundo con su propia moneda) podría convertirse en una causa fatal para la destrucción industrial y el desempleo masivo. Algo lógico: esta gran falla pasaba inadvertida si el ritmo de crecimiento permitía camuflar los desequilibrios.

Pero la expansión del crédito ha terminado, y en su lugar hay contracción de crédito y falta de liquidez. Ahora los desequilibrios estructurales y el desempleo masivo adquieren mayor relevancia cada día que pasa. ¿Qué se puede hacer para aumentar el empleo y potenciar la demanda, que dé un impulso a la reactivación económica? Esta respuesta nadie la quiere enfrentar porque la corrección de estos desequilibrios requiere revertir el propio proceso de la globalización y reindustrializar aquello que fue destruido. Solo la creación de empleo puede detener la crisis y esto implicará necesariamente resetear gran parte del proceso de la globalización.

Por lo expuesto, muchos consideran que el dólar es el principal enemigo de la economía de los Estados Unidos, ya que al ser la moneda con mayor reserva mundial, genera un estancamiento económico del país, lo que a su vez lleva a una constante presión revaluatoria, que termina encareciendo la producción exportable norteamericana e incentivando las importaciones, con las consecuencias en el desempleo

No se puede dejar de lado que tras la ruina de Bretton Woods, el dólar se convirtió en la moneda de reserva mundial por excelencia, sin respaldo en oro directo, y eso favoreció a Estados Unidos mientras su sector industrial era altamente competitivo. A medida que Japón primero, Europa y China después, comenzaron a incrementar su peso económico en el mundo, el saldo comercial comenzó a dar vuelta. De ahí que el economista Kenneth Austin, en su trabajo en el Diario de Economía Poskeinesiana (Journal of Post Keynesian Economics), señalara que Estados Unidos debía renunciar a la condición del dólar como moneda de reserva mundial, si se quiere facilitar la recuperación económica del país. 
El artículo de Austin encontró gran acogida en Jared Bernstein, economista jefe entre 2009 y 2011 del vicepresidente de Estados Unidos, Joe Biden, y miembro del equipo económico de Barack Obama. (Kenneth Austin, 2014)

Dicho economista señalo que el papel del dólar como moneda de reserva mundial pasó a ser "un principio fundamental de la política económica de Estados Unidos", según dijo New York Times, sin importar que el interés principal del país debería ser que su moneda está en manos de bancos y gobiernos extranjeros como moneda de reserva, algo que en realidad hoy "es malo para la economía de Estados Unidos"

"Una nueva investigación (dice Bernstein refiriéndose al trabajo de Austin) muestra que lo que antes era un privilegio hoy en día es una carga. Los déficit presupuestario y comercial solo permiten inflar las burbujas financieras y no hacen nada por el empleo. Si se quiere poner a la economía estadounidense en el camino correcto, el gobierno debería terminar su compromiso con el estatus del dólar como moneda de reserva y permitir su caída".

Por igual Bernstein señalo entonces que en las actuales circunstancias, países como China, Singapur y Corea del Sur reducen el valor de cambio de sus monedas frente al dólar dado que logran comprar grandes cantidades de dólares lo que aumenta el valor relativo de dicha moneda y como resultado de ello y de esa acumulación de reservas en dólares, el déficit comercial de Estados Unidos alcanzó el año 2013 unos 475 mil millones de dólares, sólo con China Estados Unidos tuvo un déficit comercial de 318 mil millones de dólares. (Kenneth Austin, 2014)

Andranik Migranyang, Director del Instituto de Democracia de Nueva York en su artículo El mito del excepcionalísimo estadunidense, publicado en la revista The National Interest, manifiesta que es importante considerar que los estadounidenses se consideran a sí mismos una nación excepcional desde hace siglos, solo ahora empiezan a darse cuenta de las dificultades que tienen, subraya el politólogo. El término 'excepcionalísimo estadounidense' fue acuñado por el historiador francés Alexis de Tocqueville en su obra 'La democracia en América' 
(1835-1840). A partir de los años 20 del siglo pasado, el término empieza a utilizarse ampliamente. El currículo de las universidades del país incluye un curso titulado 'El excepcionalísimo estadunidense.

La pérdida de hegemonía del dólar está, por tanto, no solo vinculada al menor poder económico y reducción de la productividad del trabajo estadounidense, sino a otras perdidas no económicas muy importantes desde el punto de vista subjetivo, a la hora de considerar el valor de algo que no tiene valor propio, por ser un papel moneda. (Krugman, Obstfeld, \& Meltiz, 2012)

Hace tiempo que el sistema político estadounidense ya no es un patrón que muchos países intentan copiar y no pocos estiman que hoy en día, la Constitución del país, un orgullo nacional y otra base de su mito sobre el 'excepcionalismo', esta anticuada. En cuanto a la política exterior del país, tampoco resultó eficaz, concluye Migranyan. Las campañas en Irak y Afganistán no lograron los objetivos ni estabilidad en la región. Junto con Francia e Italia, Estados Unidos intervino en Libia y eliminó el poder estatal del país como tal.

El profesor Randall Schweller, de la Universidad de Ohio, en junio de 2014 desglosa en un artículo publicado en la revista 'Foreign Affairs' por qué cree que el mundo ya no estará bajo el liderazgo de una superpotencia. En ese sentido, el experto cree que en términos geopolíticos se ha pasado a la era de la entropía. "La entropía es un concepto científico que mide el desorden: Cuanto mayor es la entropía, mayor es el desorden. Y el desorden es, precisamente, lo que va a caracterizar el futuro de la política internacional", sostiene Schweller.

\section{El yuan.}

De acuerdo con el grupo financiero SWIFT, la divisa china entró en la lista de las diez monedas más negociadas, las transacciones con el yuan se han más que triplicado en los últimos años. En 2013 alcanzaron los 120.000 millones de dólares, supera al euro y se ha convertido en la segunda moneda más utilizada después del dólar. 
Es claro que Pekín pretende utilizar su creciente influencia en el mundo con el fin de consolidar su liderazgo global y en Asia, según expertos del centro de investigación RAND en su artículo en la revista 'The Diplomat 'pero su afán expansivo pasa también por su creciente alianza con Rusia, en casi todos los temas esto es, económicos, científicos, militares y en América Latina, otro lugar de confrontación con los intereses tradicionales estadounidenses.

En este contexto, el peso chino en el comercio mundial no ha dejado de crecer, en abril de 2014, de acuerdo a lo que informa South China Morning Post, al menos 40 bancos centrales habían invertido en el yuan chino, y esta cifra prometía ir en aumento cuando los bancos centrales estaban añadiendo el yuan a su cartera e iba transformando a la moneda china en un activo de reserva internacional, compitiendo de forma creciente con el dólar y el euro principalmente. Esto hace que la brecha que separa al yuan de ser una moneda de reserva mundial cada día se acorta.

Es importante tener presente, que una de las razones que fortalece a la moneda china, es la dinámica de sus vínculos comerciales en bienes y servicios y sus crecientes exportaciones de capital a Asia, Europa y América Latina. En eso se apoyan los empresarios y banqueros chinos, en su presencia en importantes centros financieros europeos como Frankfurt, la primera zona de comercio que transo libremente en euros y yuanes. (Pugel, Economía Internacional , 2004)

Confirmando esta tendencia, a fines de 2014, Austria, Noruega, Francia y Lituania han declarado oficialmente que sus bancos centrales atesoran la moneda china. En Asia: Australia, Hong Kong, Indonesia, Japón, Corea del Sur, Macao, Malasia, Nepal, Pakistán, Singapur y Tailandia han confirmado al yuan como moneda de reserva, y por tanto atesorada por sus bancos centrales. Países de América del Sur como Chile, Bolivia y Venezuela, así como los africanos Kenia, Ghana, Sudáfrica, Nigeria y Tanzania han señalado también que caminan en esa dirección.

Si bien el dólar sigue siendo la moneda de reserva más extendida del mundo, su tenencia ha ido decayendo en los últimos años. En 2013 representaba el $33 \%$ de 
las reservas de divisas mundiales, esto es una proporción bastante menor si consideramos que el año 2000 , el 60 por ciento de las reservas mundiales de divisas estaban denominados en dólares estadounidenses. Aunque el FMI no da a conocer el porcentaje de las reservas mantenidas en yuanes por los países, la cuota de reservas en "otras monedas" ha aumentado un 400 por ciento en los últimos diez años. Esto indica que el número de bancos centrales en camino de agregar el yuan a sus carteras va en aumento. (Tugores, 2006)

En 2010 solo el 3\% del comercio exterior de China se realizaba en yuanes, en 2014 esta cifra aumentó seis veces, llego al 18\%. Hongbin indicó que en 2015 más de la mitad del comercio exterior de China con los países en desarrollo se realizará en yuanes, y cinco años después el $30 \%$ del volumen total del comercio exterior se realizará en la moneda china.

El papel del yuan en la inversión también está creciendo. China mostró su peso en el mercado mundial con la colocación en Londres de bonos valorados en yuanes. Pekín está abriendo gradualmente sus puertas a los mercados mundiales. Por primera vez en muchos años, en la Bolsa de Valores de Londres comenzó a negociarse el fondo de inversión chino.

Esta posición siguió consolidándose y el 26 de agosto de 2014, la guerra de divisas escalo un nuevo peldaño con el acuerdo cerrado en Frankfurt entre el gobierno chino y el principal centro financiero de Europa, cuando el banco de china invito a los bancos alemanes a utilizar su servicio de compensación en yuanes y el Deutsche Bank firmó como su primer cliente. Este anuncio consolido para China la creación de un centro europeo para el comercio en yuanes, después del realizado en Londres con la libra esterlina.

Europa representa aproximadamente el $10 \%$ del comercio global en yuanes y los pagos en esta moneda se han duplicado en el Reino Unido y Alemania en lo que iba del año 2014, de acuerdo a los datos de la sociedad de telecomunicaciones financieras interbancarias (swift, por sus siglas en inglés). Un tercio de todas las transacciones a nivel mundial (más de 1,3 billones de dólares), era procesado por el banco de China, de acuerdo a su presidente Chen Siqing, de ahí que el sistema 
de compensación inaugurado en Frankfurt fuera importante para la optimización del comercio entre China y Europa. (Blog Salmón, 2014)

\section{Proyectos monetarios chinos.}

El banco HSBC pronóstico que en 2015, el yuan será una de las tres monedas comerciales más activas del mundo, y dentro de dos o tres años se convertirá en una moneda totalmente convertible. Según publicó el experto Qu Hongbin, de HSBC, la evolución de la moneda china se llevará a cabo en tres etapas: el yuan debe convertirse, primero, en divisa de comercio mundial; segundo, en moneda de inversión; y, por último, en moneda de reserva mundial. (HSBC, 2014)

A finales de marzo de 2014, el Banco de Inglaterra y el Banco Popular de China acordaron fundar en la capital británica un centro de liquidación de operaciones en yuanes. Actualmente, la capital británica acoge el $62 \%$ de los pagos en yuanes realizados fuera de China.

Según el experto de HSBC, el yuan pronto estará listo para ocupar sulugar entre las principales monedas del mundo, "cuya característica distintiva es la plena convertibilidad". No obstante, la divisa china sigue siendo parcialmente convertible: a diferencia de otras monedas, cuyo curso depende de la oferta y la demanda, el tipo de cambio del yuan es fijado diariamente por el Banco Popular de China, con una variación máxima del $1 \%$. Se espera que China logre la plena convertibilidad del yuan dentro de dos o tres años.

"Sin embargo, esto no significa que el yuan vaya a reemplazar al dólar como moneda de reserva dominante, sino que ayudará a crear un sistema de múltiples monedas de reserva, en el que el dólar, el euro y el yuan tendrán su propio papel", concluyó Hongbin. En una encuesta de febrero de 2014, realizada por la unidad de negocios con sede en Londres, The Economist Intelligence Unit, por encargo de los servicios financieros State Street, donde se encuestó a 200 ejecutivos de alto nivel de inversores institucionales, quienes manejan activos en yuanes, la mitad pertenecientes a empresas con sede en la parte continental de China (más Hong Kong y Taiwán) y la otra mitad se basa en otras partes del mundo, concluye que a 
finales de 2013, el yuan llegó a convertirse en la segundo moneda de financiamiento para el comercio más utilizada y la novena divisa más utilizada para los pagos a nivel mundial.

La mayoría, el 53\% de los encuestados, dijeron que creen que el yuan superará al dólar como la moneda principal de las reservas internacionales. En China el 62\% expresó esta opinión, frente al $43 \%$ de los encuestados fuera del país.

Solo el $11 \%$ por ciento de los encuestados dijeron que no esperaban que el yuan se convierta en una moneda de reserva. Las razones más citadas son que el yuan nunca disfrutará de suficiente liquidez en todas las clases de activos para ofrecer una opción viable como moneda de reserva, y que la gente no confiará en el yuan como un depósito de valor.

"A medida que la influencia económica de China crece, la importancia global del renminbi (el yuan) se magnificará. De hecho, mientras que durante décadas ha dominado el dólar de Estados Unidos (El 'billete verde') como moneda de reserva primaria global, muchos piensan que cada vez es más posible un mundo donde prevalezca 'el billete rojo' y el renminbi goce de una condición de primer nivel", concluyeron los autores del estudio. 
Gráfico 1. Comercio entre Rusia y China.

\section{Comercio entre Rusia y China}

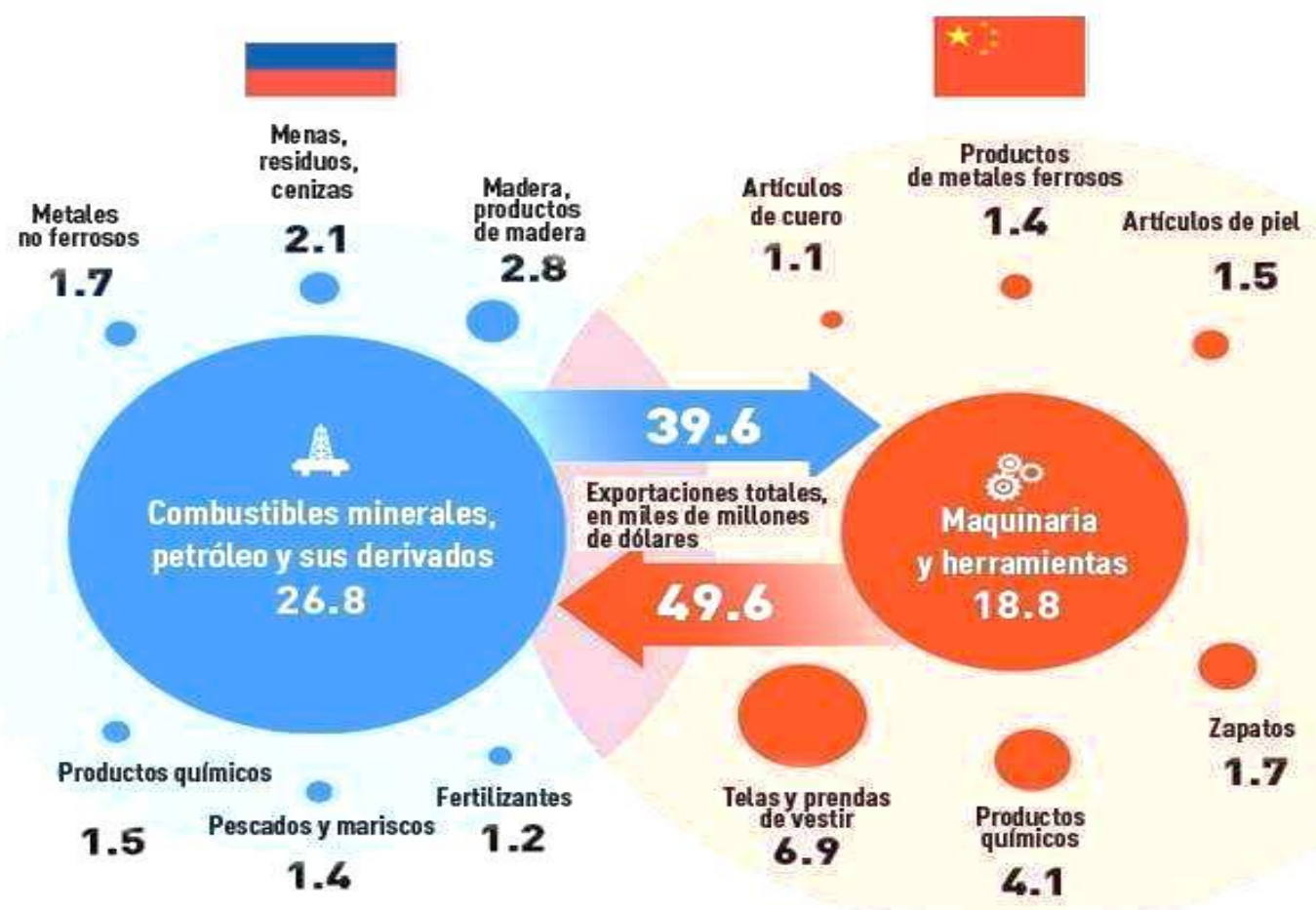

Fuente: Ministerio de Desarrollo Económico de Rusia (2013).

\section{¿Está en crisis el rublo?}

Al imponer las sanciones a Rusia, bajo el pretexto de Ucrania, Estados Unidos busca limitar el poder de Rusia y de su moneda, también eliminar o limitar los proyectos militares rusos y la competencia de la NASA en el mercado de 'servicios espaciales'. Golpea a su vez, a la Agencia Espacial Europea. Además, manifestó que las sanciones golpearan como un boomerang a ellos mismo, así como a la Agencia Espacial Europea que produce satélites a partir de elementos de fabricación rusa.

El presidente ruso, Vladimir Putin, declaro que el objetivo de las sanciones impuestas por Occidente a su país, es debilitar la independencia de Rusia y no - 
como dice Occidente- castigar a Moscú por haber arrebatado a Ucrania el control de la península de Crimea. (BBC, 2014)

En su conferencia de prensa de fin de año 2014, Putin reconoció que las sanciones han incidido en la economía de Rusia, que actualmente atraviesa dificultades, mismas que se han agravado por la caída del precio del petróleo en el mercado mundial. Ante esta situación, varios analistas pronosticaron que muchas empresas entrarían en bancarrota y no mejorara la competitividad en la industria rusa. EI IVA se incrementó y muchos precios se elevaron, el rublo se devaluó en más de $47 \%$ desde inicios de 2014 y la tasa de interés de referencia del Banco Central, pasó de 10.5 a $17 \%$.

En 2014 el país perdió aproximadamente unos 100.000 millones de dólares de las reservas internacionales, quemadas intentando defender al rublo, aunque las reservas se ubicaban en $\mathbf{4 0 0 . 0 0 0}$ millones de dólares, las deudas de las empresas del sector privado ascendían a 500.000. La gigantesca petrolera Rosneft solicito un auxilio financiero al gobierno central por 45.000 millones de dólares, lo que evidencia lo crítico de la situación económica de Rusia y del papel internacional de su moneda. En tanto los inversionistas extranjeros y nacionales estaban retirando sus capitales y se espera una recesión de 4,3\% en 2015.

La magnitud del impacto en la economía de Rusia, como consecuencia de la caída de los precios petroleros y las sanciones de los países occidentales, puede demostrarse con algunas cifras concretas.

Petróleo y gas equivalen a unos 530 mil millones de dólares por exportaciones. Sin esos ingresos, el país enfrentará un descomunal déficit en su comercio, el gasto público depende casi por completo de los ingresos vinculados al sector de energía. Sin ese soporte, el gobierno de Vladimir Putin tendrá que incurrir en un endeudamiento de $10 \%$ por año, según proyecta el FMI. 
Gráfico 2. Presupuesto de Rusia.

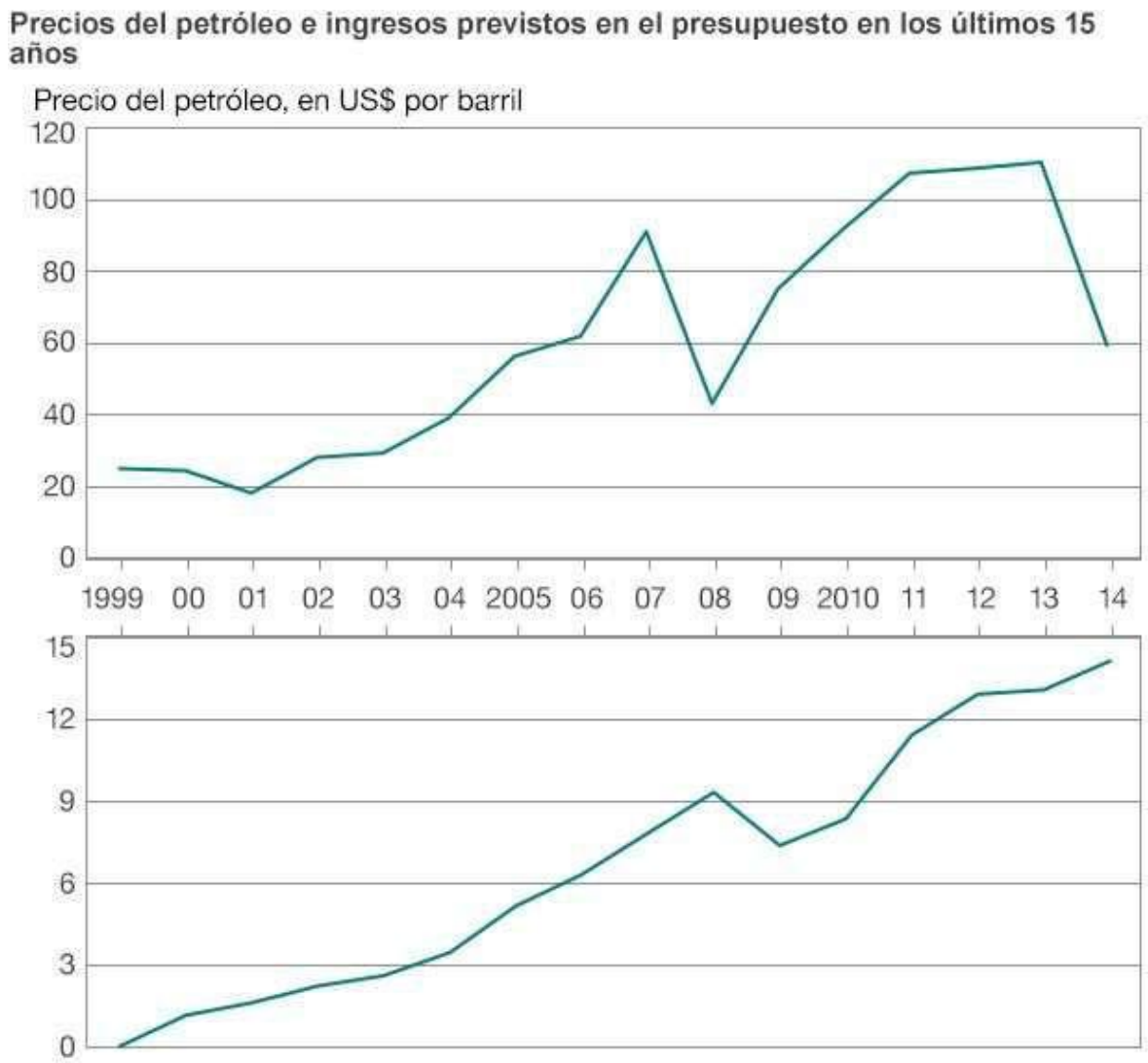

Presupuesto de Rusia en billones de rublos

Fuente: Estadísticas del presupuesto estatal ruso (actas y datos del Ministerio de Finanzas).

Con el alto déficit en el sector público y el comercio exterior, resulta muy fácil entender por qué los inversionistas no quieren tocar el rublo, y a esto se suma el efecto de las sanciones impuestas por los países de Occidente a Rusia.

En dicha coyuntura de ataques contra su economía y moneda, Rusia se movió hacia China de forma acelerada y cambio los logos de Visa y MasterCard, por otras tarjetas con tres palabras estampadas: "China. Unión. Pay". El sistema de pagos chino que ya ha empezado a emitir sus tarjetas en Rusia y se esperaba disponer de 2 millones de tarjetas en los próximos tres años.

\section{Efectos internacionales de la crisis del rublo.}


En un reporte de la agencia británica Reuter, del 19 de enero de 2015, se señalaba que las economías de la antigua ex URSS, Armenia, Georgia, Ucrania, Uzbekistán y al menos otros cinco países más, dependen en gran medida de las remesas de dinero de Rusia, para su equilibrio financiero, y en algunos de estos lugares la pérdida de valor del rublo podría generar serios problemas económicos y sociales y hasta políticos, según pronostica el diario 'The Guardian 'citado por la agencia señalada.

Tal idea estaría fundamentada en cálculos del Banco Mundial, según los cuales, tales países podrían tener dificultades ante la pérdida del valor del rublo, aproximadamente 10.000 millones de dólares en 2015. La crisis del rublo a enero de 2015 provoco la devaluación de las monedas de varias ex repúblicas de la ex URSS. Igualmente, según el Banco Mundial, en promedio, el $23 \%$ de las economías de Tayikistán, Kirguistán, Moldavia, Armenia, Ucrania, Uzbekistán y Georgia, dependen de las transferencias entre particulares desde Rusia. Muchos inmigrantes se plantean abandonar Rusia en busca de un destino mejor.

\section{La mirada rusa china.}

Los mayores bancos de Rusia, como VTB, Gazprombank, Promsviazbank, Alfa Bank, MTS y Rosbank, creaban plataformas para el empleo de los medios de pagos chinos.

En marzo de 2014, Visa y MasterCard bloquearon las cuentas de los titulares de tarjetas en los bancos Rossiya y SMF, que fueron sancionados tras la reunificación de Crimea y la ciudad de Sebastopol a la Federación de Rusia. Especialistas consideran que China UnionPay será una solución temporal para Rusia, que le permitirá dejar de depender de Occidente, mientras prepara su propio sistema de pago, que comenzaría a funcionar no antes de 16 meses. 
Gráfico 3. Tarjetas de crédito.

\section{Mayores sistemas globales de pago}
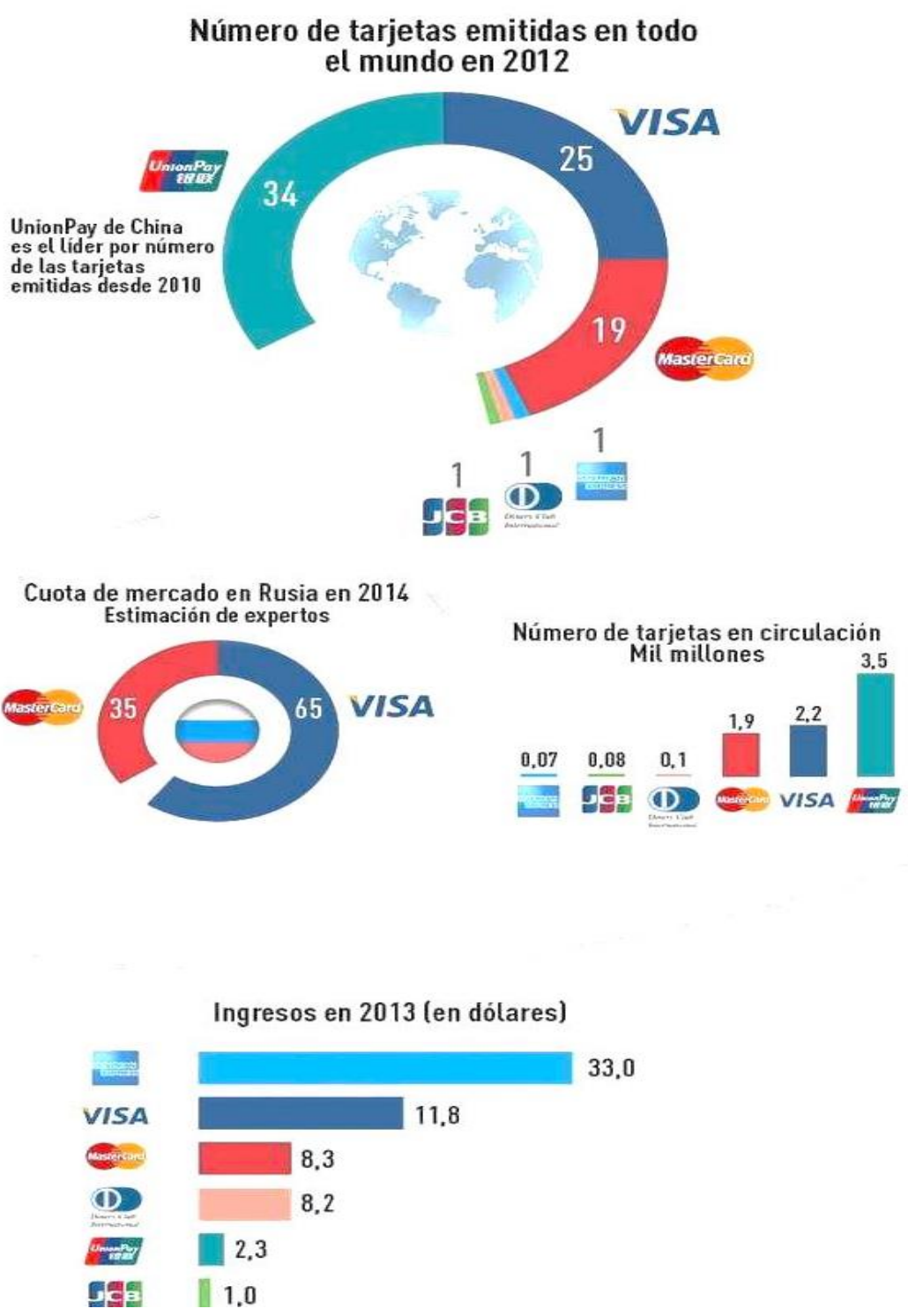

Fuente: China UnionPay, RBK, Vedomosti. Servicio de atención al cliente en Rusia.

\section{MATERIALES Y MÉTODOS}

Para la realización del presente artículo, los datos se obtienen por observación y medición de fuentes estadísticas externas pertenecientes a los Estados analizados y a instituciones públicas y privadas del mundo. El análisis de datos, usando series 
de tiempo, describe la tendencia de las variables y compara su relación entre ellas. Al describir las variables se busca explicar sus cambios y movimientos en el tiempo, mediante el análisis estadístico.

El análisis de la información pretende eliminar la subjetividad y los criterios de evaluación también son objetivos, rigurosos y confiables. Los resultados obtenidos se pueden comparar con los hallazgos encontrados en estudios previos. La investigación pretende ser integral, porque abarca el todo; es sistemática, porque no deja nada a la casualidad; empírica, porque se basa en la realidad; delimitada a un hecho concreto; objetiva y flexible, porque elimina juicios de valor; y crítica, porque lo hace constantemente con información real. La crítica veraz, objetiva, transparente y oportuna demuestra con datos y argumentos robustos la verdad de los hechos.

La investigación deduce realidades presentes. Además, utiliza los métodos científicos de inducción, síntesis y análisis para distinguir los elementos del problema que se investiga. La técnica utilizada es la documental, sustentada en libros, revistas especializadas y estadísticas oficiales. La investigación se realiza en un período de tiempo que va desde el 2014 al 2016. En este tiempo, se procede a la recolección de la información, análisis e interpretación de la misma, ajustes, redacción y revisión.

\section{CONCLUSIONES}

La dinámica de estos problemas monetarios mundiales, ya vimos, no solo depende del propio signo monetario, sino que en ello influyen equilibrios de poder económico, político y militar, los cuales determinan el papel de las diferentes monedas (papel moneda) que actúan en la circulación monetaria global, separadas cada día más de sus equivalentes en oro y otros metales preciosos y hasta de las mismas mercancías, tal parece que ahora pesan cada día menos estos factores materiales en el lugar de cada una de las monedas globales y de aquellas que aspiran a ser calificadas como tales. 
Es una tarea compleja darle seguimiento al movimiento del dinero (más bien del papel moneda) en la dinámica mundial, pues su velocidad y vías de transformación, cual una metamorfosis, continua, es muy compleja, al punto de ser muy difícil darle seguimiento a todas ellas. Sin embargo, hay algunas verdades que se pueden decir y es que sobre todo estamos en presencia de movimientos telúricos de la economía mundial y su esfera de la circulación internacional del dinero, donde Estados Unidos y su moneda parecen resurgir y querer recuperar su perdido espacio global.

Estados Unidos, dejó de ser el principal importador de crudo del mundo y es muy posible que dentro de poco pase a ser exportador neto de combustibles, esa sola premisa arrastra todo el balance de poder de las monedas internacionales, y además indica que en el fondo de la lucha monetaria entre los principales actores de la economía mundial hay una competencia por el mercado global, donde la fortaleza de las monedas juega un papel significativo.

El lugar de las confrontaciones militares y la carrera por la supremacía militar, hoy con nuevos matices, también influye en esta situación de confrontaciones monetarias.

Estudio aparte merece el caso de la libra esterlina, moneda británica, que a pesar del tiempo, ha resistido los embates del euro primero y después de las ataques de las nuevas monedas como el yen, el rublo y el yuan, siendo hoy por hoy la de mayor valor comparativo a la hora de establecer las complejas tasas de cambio de los signos monetarios de los diferentes países.

Creemos entonces, que vienen años de cambios significativos en la economía mundial globalizada, y por tanto de reajustes de la importancia relativa de las monedas que se utilizan mayormente en los movimientos de mercancías y capitales globales por lo que es de esperar acomodos y reacomodos entre el dólar, la libra esterlina, el euro, el yuan, el yen y el rublo, buscando el predomino mundial, sin dejar de lado a otras monedas que lucharan por mantener su territorio fuera de la penetración de los demás. 


\section{REFERENCIAS BIBLIOGRÁFICAS}

Krugman, P., Obstfeld, M., \& Meltiz, M. (2012). Economía Internacional. México: Pearson Educación SA.

Leal, P. (10 de Diciembre de 2015). HISPANTV. Obtenido de http://www.hispantv.com/noticias/opinion/83381/estados-unidos,-psicosis-ypolitica-exterior

Legarde, C. (2014). Elegir bien, ayer, hoy y mañana. Washignton.

Levi, M. (1997). Finanzas Internacionales. México: Mc Graw - Hill.

Ley de prevención de la agresión Rusa. (26 de Agosto de 2014). Periodismo alternativo. Obtenido de https://periodismo-alternativo.com/2014/08/26/leyde-prevencion-de-la-agresion-rusa-camino-al-desastre-mundial/

Mishkim, F. (2008). Moneda, Banca y Mercados Financieros. México: Pearson Educación .

Observatorio Económico Asia - Pacífico. (2014). Foro de Cooperación Económica Asia Pacífico (APEC). (págs. 1-9). Beijin: APEC.

Pugel, T. (2004). Economía Internacional. Madrid: McGraw Hill.

Tugores, Q. (2006). Economía Internacional, Globalización e integracion regional. Madrid: Mc Graw - Hill.

Wroughton, L. (4 de Octubre de 2014). Reutes America Latina. Obtenido de http://ta.reuters.com/article/worldNews/idLTAKCNOHTOQF20141004 
BBC. (12 de Diciembre de 2014). www.bbc.com/mundo. Obtenido de http://www.bbc.com/mundo/internacional

Blog Salmón. (19 de Abril de 2014). La guerra de divisas escala a nueva guerra fría con final abierto. Obtenido de https://www.elblogsalmon.com/categoria/economia

HSBC. (4 de Abril de 2014). www.hsbc.com. Obtenido de https://actualidad.rt.com/economia/view/124321-hsbc-yuan-monedareserva-mundial-china

Kenneth Austin. (2014). El dólar es el principal enemigo de la economía de Estados Unidos. El Salmón, 3.

Selva. (9 de Diciembre de 2014). www.selva.org.co/home-2/. Obtenido de http://selva.org.co/publicaciones/

TeleSUR. (24 de Diciembre de 2014). www.telesurtv.net. Obtenido de http://www.telesurtv.net/

\section{Licencia Creative Commons}

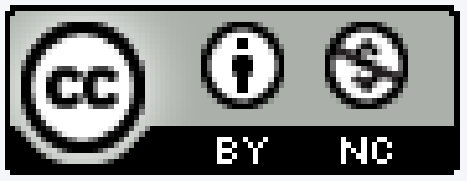

Revista Científica ECOCIENCIA está bajo una Licencia Creative Commons Atribución-NoComercial 4.0 Internacional. 